\title{
Operant responding of redtailed and Cooper's hawks to continuous reinforcement
}

\author{
J. M. WHITT AND F. T. CRAWFORD \\ FLORIDA STATE UNIVERSITY
}

Two redtailed hawks (Buteo jamaicensis borealis), and two Cooper's hawks (Accipiter cooperii) were trained to make a key peck response for $.64 \mathrm{~cm}$ cubes of beef heart which had been trimmed of fat. Each bird received 15 daily sessions during which each key peck produced reinforcement (continuous reinforcement). Each session was approximately $20 \mathrm{~min}$ long. The birds acquired the responses readily and the rates were generally comparable.

Birds have long been of scientific interest to both the naturalist and the laboratory investigator. Operant control of behavior in birds has been primarily concerned with pigeons, but data for doves, crows, ducks, quail, and chickens, among others, have been reported. There appears to be only one study in the literature which has employed carnivorous birds. Witoslawski, Anderson, \& Hanson (1963) observed the behavior of a black vulture (Coragyps atratus) under variable and fixed interval schedules, fixed ratio schedules, and drug conditions. They concluded that behavioral studies of large carnivorous birds were feasible and that it should be possible to investigate behavioral capacities previously only inferred from observations in the field. The present report is concerned with the operant behavior of two other species of predatory birds under conditions of continuous reinforcement.

Subjects

Two redtailed hawks (Buteo jamaicensis borealis) and two Cooper's hawks (Accipiter cooperii) were the Ss of the experiment. They were captured in the Big Bend area of northern Florida. The redtailed hawks, Horus and Nike, were captured as nestlings and raised and gentled in the laboratory. At the end of the experiment Horus and Nike were estimated to be nine months old, and were approximately 48.3 and $52.1 \mathrm{~cm}$ in height, and 1.86 and $2.0 \mathrm{~kg}$ in weight, respectively. The Cooper's hawks, Ptah and Thoth, were approximately 12 and 16 months old at the end of the experiment, and were about 31.1 and $33.0 \mathrm{~cm}$ in height and 7.2 and $8.6 \mathrm{~kg}$ in weight, repectively. Ptah was obtained from a local institution which desired to dispose of the bird because of a broken wing. Thoth was captured while still immature. All of the hawks were female.

The Ss were maintained on fresh beef heart, supplemented with a vitamin powder, and were given, in addition, a live rat or young chicken once a week except during the period of data collection. The beef heart was always trimmed of fat before feeding to the birds. Beef heart fed to these birds must be fresh, and preferably non-frozen, or the birds will refuse to eat.
It was not necessary to provide fresh water since the food regimen supplied a sufficient fluid intake. Since the birds were immature they were not reduced in body weight during the experiment.

\section{Apparafus}

The test chamber was a modified ice box chassis containing a blower, house light, an adjustable bird perch, peck response key, and a Foringer liquid reinforcer which was equipped with an enlarged cup serving as a magazine. The magazine was circular and had a diameter and depth of 1.59 and $.32 \mathrm{~cm}$, respectively. Preliminary work with hawks indicated that response rates were best maintained when there were only a few small pieces of beef heart available at one time. A fully loaded magazine dismupted the response rate because the hawks tended to remain at the site of reinforcement. It was therefore necessary to monitor the reinforcement and delivery mechanism continuously. Each portion of beef heart was an approximate $.64 \mathrm{~cm}$ cube.

\section{Procedure}

The birds were placed in the apparatus and given the opportunity to feed from the aperiodically presented food cup (magazine training). After magazine training they were shaped to make a key peck response. Shaping was done by getting the birds to peck at a red insulated wire extended through a small hole beside the key and transferring the pecking response to the key while gradually removing the wire. Reinforcement was given employing a remote switch during shaping. Horus took $5 \mathrm{~min}$ to magazine train, and $4 \mathrm{~min}$ and 21 reinforcements to acquire the response. Nike was given $12 \mathrm{~min}$ of magazine training followed by three daily $15 \mathrm{~min}$ sessions and a total of 973 reinforcements. Ptah was given $18 \mathrm{~min}$ of magazine training followed by two daily sessions of $15 \mathrm{~min}$ each and a total of 130 reinforcements. Thoth was given 7 min of magazine training, followed by $12 \mathrm{~min}$ and 48 reinforcements. The birds were then given 15 daily sessions during which each key peck produced a cube of beef heart (continuous reinforcement). Each session was approximately $20 \mathrm{~min}$ long.

Results and Discussion

A sample of the behavior of the birds is shown in Fig. 1. These four records for each bird are taken from the last six sessions and are typical of the terminal performances of the Ss. The mean response rate for Horus, Nike, Ptah, and Thoth were 265.8, $221.8,117.5$, and 292.2 responses/session, respectively. This is equivalent to $13.3,11.1,5.9$, and 14.6 


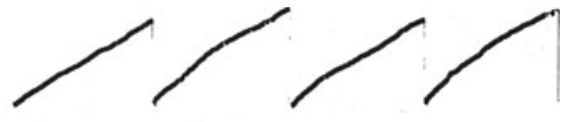

HORUS

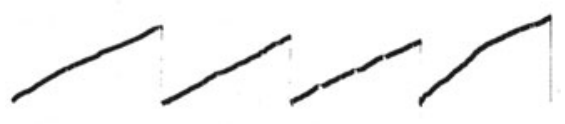

NIKE

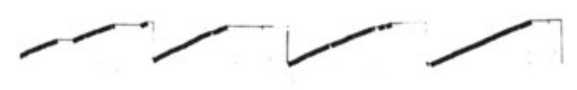

PTAH

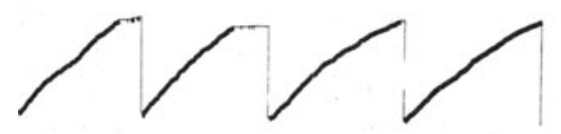

тнотн

Fig. 1. Response records of the redtailed hawks (Horus and Nike) and the Cooper's hawks (Ptah and Thoth).

responses $/ \mathrm{min}$, respectively. The response rates of the birds are comparable except perhaps in the case of Ptah. The fact that Ptah had been captured by others, and thus had an unknown history of association with humans, plus a broken wing of long standing, may have been a critical factor in the lower response rates observed. Because of the broken wing Ptah was not handled except to place her in and remove her from the apparatus. The bird was therefore not as gentle and docile as the others.

Following the 15 sessions of continuous reinforcement, training on fixed and variable intervals was attempted. The initial superiority of the Cooper's hawk, Thoth, was not maintained on these schedules. Although responding of the redtailed hawks persisted longer with increased interval length between reinforcements, the response rates of all birds fell off. It was tentatively concluded that Cooper's hawks are less satisfactory Ss than redtailed hawks. This observation is consistent with the reputation of the Cooper's hawk for being difficult to train and use in the field. The decline in response rate was apparently brought about by inconsistencies associated with reinforcement delivery. The birds appeared to be very sensitive to small variations in experimental procedures despite the efforts of the Es. A device is currently being developed which will automatically deliver reinforcement in a consistent and uniform manner. In spite of the difficulties in presenting reinforcement, it may be concluded that the hawk is a suitable and interesting $S$ for operant work, requiring only minor modification in methodology. The feasibility of using such Ss raises interesting questions concerning their visual acuity, discrimination, and binocular vision, as well as their behavioral capacities.

\section{Reference}

Witoslawski, J. J., Anderson, R. B., \& Hanson, H. M. Behavioral studies with a black vulture, Coragyps atratus. J. exp. Anal. Behav., 1963, 6, 605-606. 